\title{
Nutrition and the growth and racing performance of thoroughbred horses
}

\section{By D. L. Frape, Cantab Ltd, Alexandra House, Hinchingbrooke Hospital, Huntingdon, Cambs PE18 8NT}

Throughbred (TB) breeders assert that 'strong bone' is an important characteristic to be fostered, notwithstanding an apparent need for rapid growth and development imposed by the commitment of many $T B$ to the race track at 2 years of age. Nevertheless, there has been little measurement of post-natal growth of TB in the British Isles, even though there is a considerable wastage, and an inevitable monetary loss, from clinically observable abnormalities in conformation and breakdown of horses in training. Jeffcott et al. (1982) estimated that over $30 \%$ of TB born did not run at 2-4 years of age.

Whereas what might be termed the chronic nutrient requirements of horses have been, in large measure, estimated by inference from observations in other domestic species, this approach may be appropriate neither to the resolution of the major equine growth defects, nor to the acute nutrient and feed requirements associated with imminent exercise (Frape, 1988). The purpose of the present paper is to address the nutritional aspects of these issues.

\section{Growth in foals}

Despite an absence of any concerted breeding selection for growth, indices of this characteristic show that the rate in TB suckled foals, as a function of time (Fig. 1) and of body-weight (Table 1), is similar to that of suckled calves of large-breed crosses (calf values from P. J. Broadbent, personal communication; foal values collected from three TB studs).

In order to contain, or avoid, skeletal defects during the growth of TB, breeders have frequently limited the protein content of supplementary feeds so that rate of growth is restricted. Rate of growth in young foals reflects the rate of milk secretion of the dam. Oftedal et al. (1983) found milk outputs of 149,139 and $163 \mathrm{~g} / \mathrm{kg}$ body-weight ${ }^{0.75}$ at 11,25 and $39 \mathrm{~d}$ post partum respectively. Equine milk contains approximately $2 \cdot 1 \mathrm{MJ}$ gross energy (GE)/kg (a total of $36 \mathrm{MJ} \mathrm{GE}$ daily from a $550 \mathrm{~kg}$ mare). Peak milk yield per d was achieved by a group of Quarter Horse mares $30 \mathrm{~d}$ post partum (Gibbs et al. 1982). Under most husbandry systems, the rate of milk secretion by TB mares must largely depend on the productivity of grazing areas allotted to them, although mares are

Table 1. Rates of body-weight gain in thoroughbred suckled foals and suckled calves of large-breed crosses

\begin{tabular}{lccc} 
& \multicolumn{3}{c}{$\begin{array}{c}\text { Wt gain/week per unit body-weight* } \\
\text { (kg/week per kg) }\end{array}$} \\
\cline { 2 - 4 } & Calves $\dagger$ & Stud 1 & Stud 3 \\
Birth & 0.223 & 0.123 & 0.246 \\
2 weeks & 0.076 & 0.095 & 0.159 \\
30 weeks & 0.029 & 0.018 & 0.021
\end{tabular}

*Body-weight at the commencement of a 2 week period over which the gain was measured.

tCharolais $\times$ Hereford Friesian and Charolais $\times$ Blue Grey calves weaned at 8 months of age; values derived from those of $\mathbf{P}$. J. Broadbent (personal communication). 


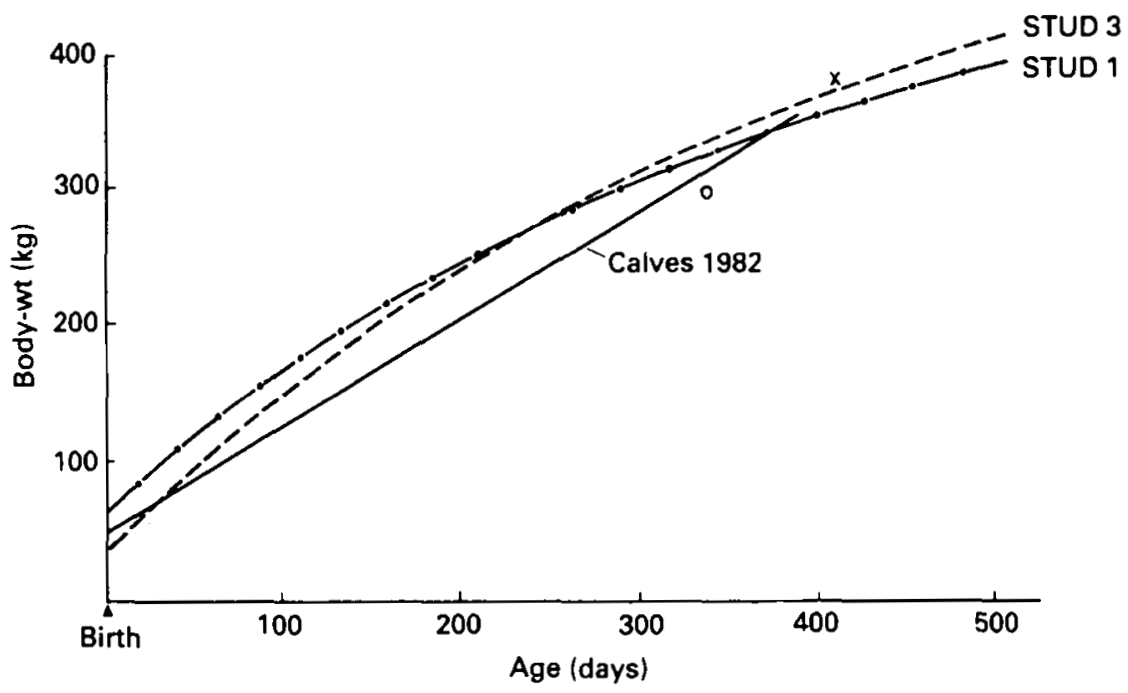

Fig. 1. Growth curves of fifty-eight Charolais $\times$ Hereford Friesian and Blue Grey suckled calves, weaned at 8 months, and of forty-eight Thoroughbred foals weaned at 4-5 months. Calf values from P. J. Broadbent (personal communications).

Stud 3, W/560 $=1-e^{-0.0025(t+27)}$

Stud $1, W / 500=1-e^{-0.0027(t+52)}$

Calf $\mathrm{W}=52 \cdot 2+0.844 t$

\begin{tabular}{cc}
\multicolumn{2}{c}{ SE } \\
\hline$A$ & \multicolumn{1}{c}{$b$} \\
$0.45 \%$ & 0.0001 \\
$0.14 \%$ & 0.00001 \\
2.77 & 0.01381
\end{tabular}

$W$, body-weight; $t$, age.

Stud 2, individuals: (0), joint flexural deformity; (X), physitis.

typically offered supplementary feedingstuffs in the stable at night, or on the pasture.

The skeletal defects to which foals are subject include physitis, angular deformities, or misalignment of long bones and joint flexural deformity (hyperflexion of the fetlock in particular), osteochondrosis dissecans, cervical vertebral malformation ('wobblers'), malformation of the cuboidal bones of the carpus and tarsus and juvenile arthritis. All these diseases are possibly manifestations of one metabolic bone disease in which there is a failure of cartilage to develop into healthy weight-bearing bone (Gabel, 1988). The incidence is thought to be increasing (Glade, 1986), and not only nutrition but heredity, conformation and the extent of exercise have all been considered to play contributory roles. Hintz et al. (1976) reproduced a condition not unlike hyperflexion by restricting access of 4-month-old foals to feed and then allowing free access. More recent work (Schryver et al. 1987) has failed to reproduce the effect by imposing a restriction on dietary protein intake and then inducing compensatory growth by providing liberal amounts of dietary protein.

In the foals examined at the three TB studs, the post-natal growth rates of individual animals found to display hyperflexion, or physitis, were within the range found in normal foals for both body-weight and height-for-age (Table 2 and Fig. 1), in conformity with previous evidence (Glade, 1986) that the occurrence of osteochondrosis in horses is independent of growth rate. Endochondral bone growth and ossification, and growth in height, are less affected by feed restriction than is body-weight gain. Stress on limb bones is said to occur when increase in body-weight per unit increase in height is large. 
Table 2. Regression coefficients of body-weight $(0-350 \mathrm{~kg}) \mathrm{v}$. height and body-weight, and height $\mathrm{v}$. age of foals (from values collected from the studs referred to on $p$. 142).

(Mean values and standard deviations)

\begin{tabular}{|c|c|c|c|c|c|c|}
\hline \multirow[b]{2}{*}{ Condition of foal } & \multicolumn{2}{|c|}{$\begin{array}{c}\text { Weight } v \text {. age } \\
(\mathrm{kg} / \mathrm{d})\end{array}$} & \multicolumn{2}{|c|}{$\begin{array}{l}\text { In wt } v .1 \mathrm{n} \mathrm{ht} \\
(\operatorname{ln~kg/1n~cm)~}\end{array}$} & \multicolumn{2}{|c|}{$\begin{array}{l}\text { Height } v . \text { In age } \\
\quad(\mathrm{cm} / \ln \mathrm{d})\end{array}$} \\
\hline & Mean & SD & Mean & SD & Mean & SD \\
\hline Normal legs & 0.67 & 0.023 & $4 \cdot 6$ & $0 \cdot 10$ & $18 \cdot 6$ & 0.54 \\
\hline Abnormal legs & $0 \cdot 61$ & 0.038 & $5 \cdot 0$ & 0.20 & $16 \cdot 0$ & 0.83 \\
\hline
\end{tabular}

Although there was no measurable difference between normal and abnormal groups for this characteristic (Table 2), weight gain of the abnormal foals had been temporarily restricted during the crisis, probably reducing the overall regression coefficient for weight, more than that for height, gain. Nevertheless if a greater ratio (weight gain:height gain) is a contributory cause of severe abnormality, then the restriction of feed intake is a reasonable management response.

TB foals are weaned at $4-6$ months of age when pasture quality is declining. Growth rates during the first winter are generally low. Faster growth rates are reinstated during the following spring, coinciding with a flush in herbage growth. Thus, growth rate is subject to vagaries in the nutritional quality of pasture, rather than to the quantity of herbage available.

A traditional and frequent anomaly in the winter diet of growing TB that may be of significance in the incidence of physitis is low dietary concentrations of calcium and excessive phosphorus, owing to large intakes of oats accompanying hay of indifferent quality. This anomaly is now less common, but physitis is probably not. A slow rate of growth of TB foals frequently observed during the first winter in part may result from inadequate dietary protein and poor-quality conserved roughage. Schryver et al. (1987) reported that foals receiving a diet containing only $90 \mathrm{~g}$ protein $/ \mathrm{kg}$ (that is not uncommon when hay quality is poor) were subject to a reduced rate of growth in cannon-bone circumference, with little effect on height growth. Long-bone remodelling seems to be inhibited by a low-protein diet, and an increased force per unit cross-sectional area may then be applied to long-bone articular surfaces. However, body-weight gain was also inhibited by the low-protein diet and the ratio, body-weight $(\mathrm{kg})$ : forecannon area $\left(\mathrm{cm}^{2}\right)$ after the first $140 \mathrm{~d}$ of the experiment was $9.2,12.1$ and 11.9 for the foals receiving respectively the diets containing 90,140 and $200 \mathrm{~g}$ protein-kg.

Glade et al. (1984) put forward an alternative explanation of skeletal abnormalities in growing foals. Grazing foals and other horses take in energy and protein-containing foods in small quantities at very frequent intervals throughout the $24 \mathrm{~h}$. Meal feeding of farinaceous diets, on the other hand, causes a large postprandial blood insulin response, which in turn foreshortens the postprandial thyroxine $\left(\mathrm{T}_{4}\right)$, response. This is caused by the early insulin activation of hepatic $\mathrm{T}_{4}$-5-deiodinase ( $E C$ 3.8.1.4) (Gavin \& Moeller, 1983 ), increasing the rate of $T_{4}$ conversion to triiodothyronine $\left(T_{3}\right)$ that acts to inhibit thyroid-stimulating hormone secretion. Cartilage growth responds to insulin and $T_{3}$. The mitogenic effects of insulin in the production of new immature cartilage require cyclic AMP stimulated by $T_{3}$. High rates of intake of digestible carbohydrate, but not of protein, or of smaller amounts of carbohydrate, cause blood $\mathrm{T}_{4}$ to peak before that of 
blood glucose, insulin or $T_{3}$ (Glade \& Luba, 1987). Moreover, high concentrations of insulin can inhibit growth hormone secretion (Phillips, 1986), although this relationship has not been examined in horses. Lack of postprandial synchrony of $T_{4}$ with insulin is speculated to suppress maturation of growing cartilage and contribute to metabolic bone disease (Glade et al. 1984; Glade, 1986; Glade \& Luba, 1987). Thus, inadequate supplementary protein and the imposition of meal feeding of foals may contribute to the disease incidence. On the other hand, there is no convincing evidence that the appropriate cellular responses to $T_{4}$, like those to insulin, are pulsed in vivo. In other species, microstructural changes occur in response to $T_{4}$, principally that of increased numbers of mitochondria per cell that should have more protracted effects.

As young TB horses enter training, food intake increases substantially, but dietary protein content changes little, despite the greater maturity of the horse. The optimum concentration for dietary protein of isoenergetic diets is decreased by increasing exercise rate, and its attendant energy expenditure, of horses fed to appetite. For example, Orton et al. (1985) demonstrated increased rates of body-weight gain in unexercised $300 \mathrm{~kg}$ Australian Stockhorses when a $120 \mathrm{~g} / \mathrm{kg}$ rather than a $60 \mathrm{~g}$ protein $/ \mathrm{kg}$ diet was given. By comparison, when such horses were trotted for $1 \mathrm{~h}$ on a rotary walker, at $12 \mathrm{~km} / \mathrm{h}$, the growth rate of horses given both these diets was similar to that of the higher-protein unexercised group. Comparable responses were obtained by Schryver et al. (1987), and the effects are attributable to a stimulation of appetite and, therefore, of feed intake in ad lib.-fed exercised horses. Observations indicate a rise in urinary nitrogen with hard routine exercise (Frape, 1987), but accompanied by increased $\mathrm{N}$ retention (intake $\mathrm{N}$-faecal $\mathrm{N}$-urinary $\mathrm{N}$ ) apparently not accounted for by greater losses of $\mathrm{N}$ in sweat (Freeman et al. 1988). The rise in urinary $N$ is likely to be associated with increased urinary sulphur and phosphorus which could increase urinary calcium loss (Frape, 1987) as observed by Glade et al. (1985). Similar observations were made in acid-stressed rats (Kunkel et al. 1986). Excessive protein consumption superimposed on training diets frequently found to contain too much $\mathbf{P}$ and too little $\mathrm{Ca}$ could aggravate existing bone disorders. Moreover, Glade (1983) observed that speed of horses in flat racing was negatively correlated with dietary protein intake. This apparent relationship may be explained by a dietary-protein-induced effect on blood acid-base status (Frape, 1987). Blood bicarbonate and base excess would be depressed, exacerbating the fatigue resulting from metabolic acidosis that exists during sprint races. This conclusion is supported by the observations of Gleeson et al. (1987) that excess dietary protein advanced time to exhaustion of male cyclists, even though these volunteers exercised only at a workload equivalent to $100 \%$ maximum oxygen consumption $\left(V_{\mathrm{O}_{2} \max }\right)$.

\section{Diet and athletic performance}

The relevance of nutrition to athletic ability of horses may be conveniently divided into that influencing long-term health and well-being, and that which might influence events during the immediate $24 \mathrm{~h}$ (Frape, 1988), when the endocrine system plays an important modulating role in the regulation of nutrient supply to muscle cells.

The dietary energy requirements of horses over periods of training may be estimated from body-weight (including that of the rider) and the time devoted to exercise and its intensity. Pagan \& Hintz (1986a) found an exponential relationship between oxygen consumption, speed and body-weight $(\mathrm{kg})$ over a given distance on level ground, yielding the following identity:

$$
Y=7 \cdot 34 e^{3 \cdot 02+0.0065 x}-102 \cdot 2
$$


where $Y$ is digestible energy (DE; $/ \mathrm{kg}$ per $\mathrm{min}$ ), $x$ is speed $(\mathrm{m} / \mathrm{min}$ ), and where energy maintenance requirement is 102.2, measured as DE (J/kg) (Pagan \& Hintz, 1986b). This non-linear outcome is probably explained by accelerating frictional losses at higher speeds.

There are infrequently facilities for weighing horses, and several procedures for predicting body-weight from linear measurements have been published so that the previously-mentioned estimates of energy requirement may be concluded. The most recent estimate derived from a large data-set was proposed by Carroll \& Huntington (1988):

$$
\mathrm{W}=\mathrm{G}^{2} \cdot \mathrm{y} / 11877,
$$

where $\mathrm{W}$ is body-weight, $(\mathrm{kg}) ; \mathrm{G}$ is heart girth $(\mathrm{cm})$ and $\mathrm{l}$ is length from the point of the shoulder to the tuber ischii $(\mathrm{cm})$.

Exercise intensity of a horse is considered to be a function of $V_{\mathrm{O}_{2} \max }$ (of the order of 104-169 $\mathrm{ml} / \mathrm{kg}$ per min compared with $80 \mathrm{ml} / \mathrm{kg}$ per min for the elite human athlete (Snow, 1987; Evans \& Rose, 1988). One effect of training is to raise $V_{\mathrm{O}_{2} \max }$ and thus to reduce the work intensity of a given speed. $V_{\mathrm{O}_{2} \max }$ is of much greater significance to longer-distance events, and is of marginal relevance to equine sprints of a duration of approximately $1 \mathrm{~min}$. In contrast hormonal, and in particular catecholamine, responses are not proportional to the amount of exercise, but rather to work intensity of human athletes (Williams, 1985) and horses (Snow et al. 1979; Snow \& Rose, 1981; Irvine, 1983). Nevertheless, the catecholamine response to exercise, especially following training, causes a rise in blood glucose (Haggendal, 1971) and a suppression of any consequential insulin secretion in human athletes (Rennie et al. 1974). TB in training are normally fed immediately following their daily exercise. Observations on five TB

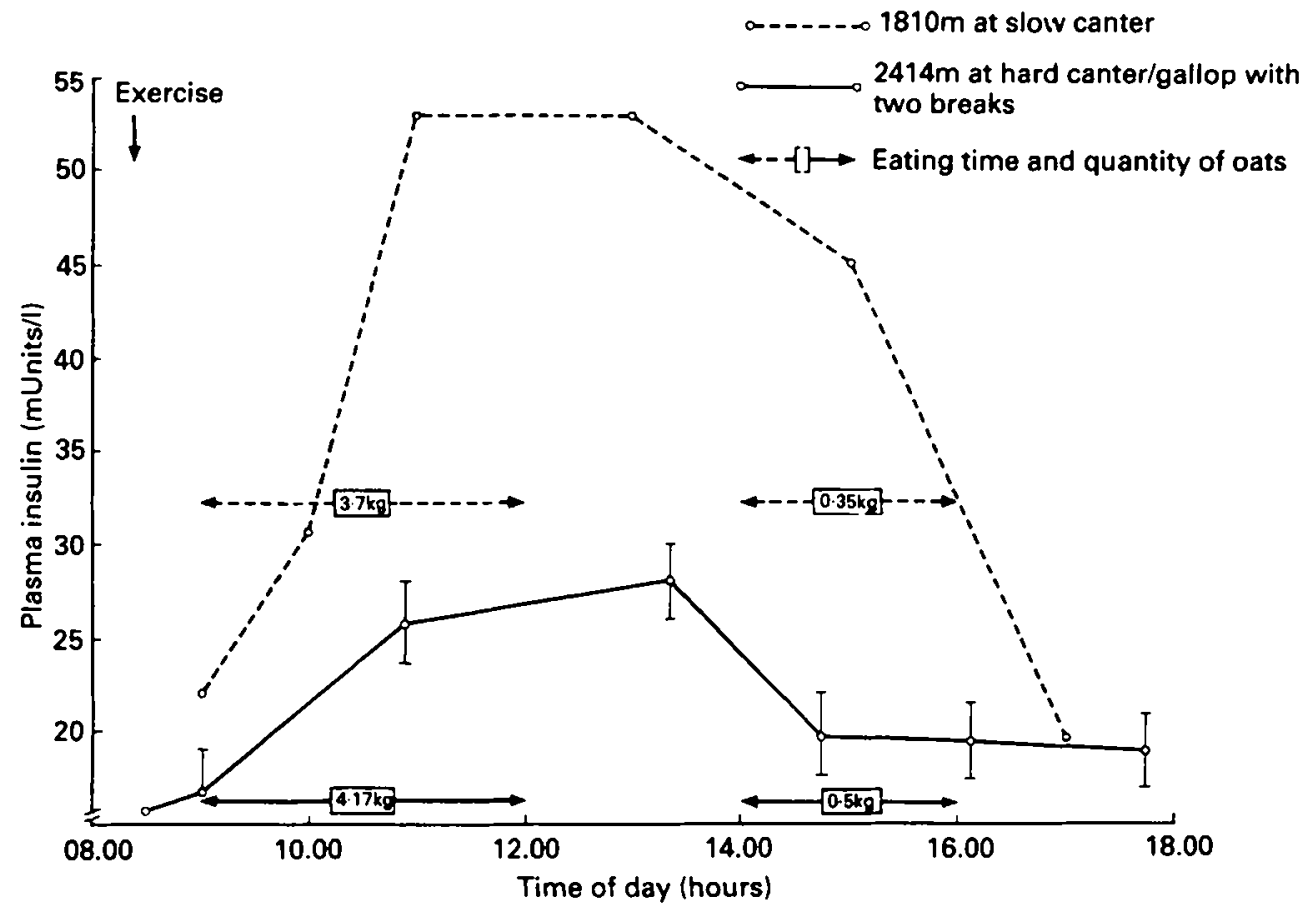

Fig. 2. Apparent effect of exercise intensity on plasma insulin response of five racehorses to diet (one, slow canter; four, gallop). Standard errors represented by vertical bars. 


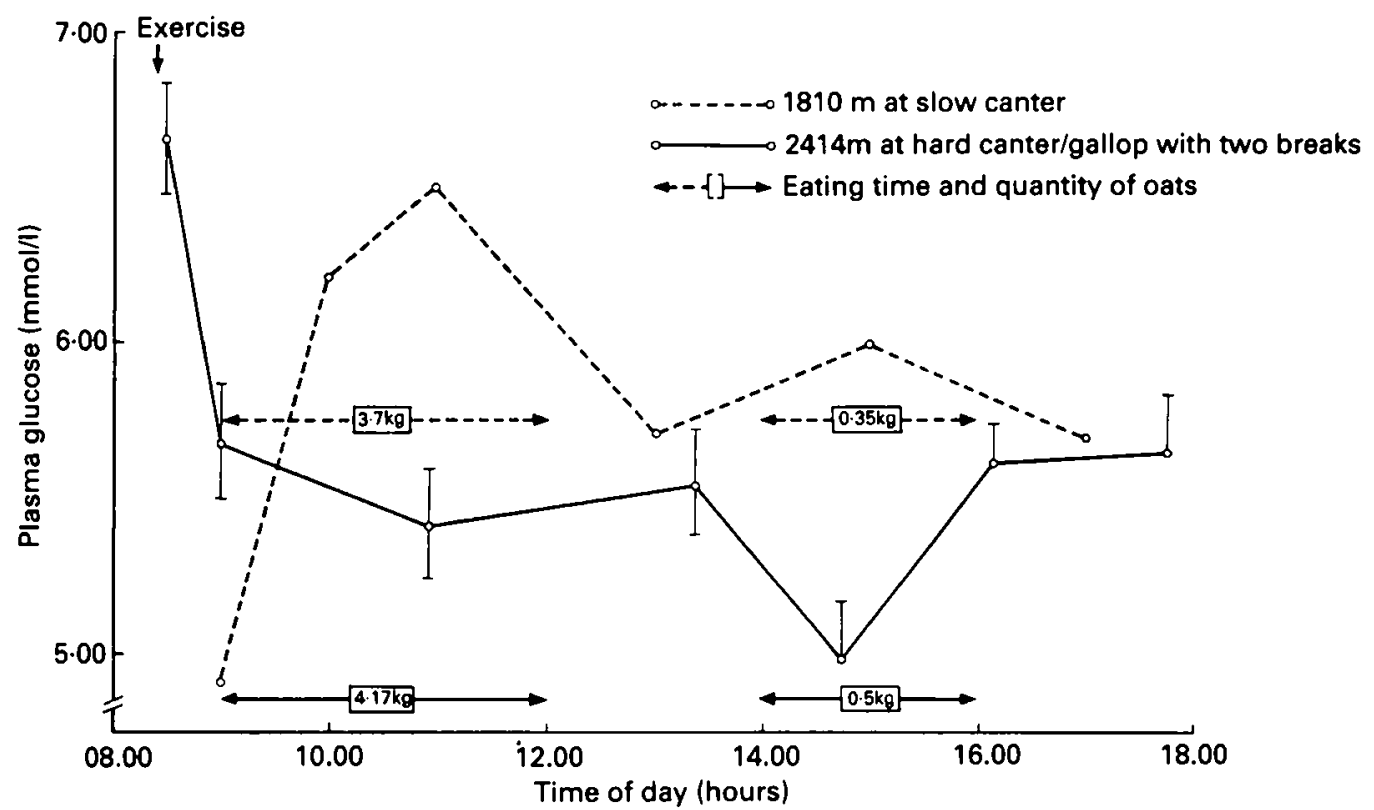

Fig. 3. Apparent effect of exercise intensity on plasma glucose response of five racehorses to diet (one, slow canter; four, gallop). Standard errors represented by vertical bars.

indicate that intense anaerobic exercise in trained $\mathrm{TB}$ seems also to depress a postprandial immunoreactive insulin (IRI) response (Fig. 2) and to suppress the normal glucose response to diet (Fig. 3). The elevation of blood glucose during exercise (Fig. 3) represents a catecholamine and, to a lesser extent, a glucocorticoid response through promotion of glycogenolysis. The suppression of postprandial blood glucose and insulin responses probably has several contributory causes. First, an exertional loss of muscle glycogen in athletes stimulates glycogen synthase (EC 2.4.1.21) activity (Costill, 1985). Second, a shunting of blood away from the coeliac vessels to increase the irrigation of muscles and to overcome post-exercise anoxia has a probable consequence of decreasing the rates of starch and protein digestion, and of glucose and amino acid absorption. These events may also decrease gastrin, secretin, cholecystokinin and gastric-inhibitorypeptide secretion that are known to stimulate insulin secretion in man (Guyton, 1981). Third, although elevated blood cortisol is unlikely to contribute to a suppression of insulin secretion, adrenalin does (Snow, 1980), by direct inhibition of $\beta$-cell function.

Intense exercise brings about a lesser increase of blood catecholamines in trained, compared with untrained, horses (Irvine, 1983) and so may cause less suppression of blood insulin. However, in the post-exercise response to feeding no difference was found in blood insulin level that could be related to fitness of the five TB, as assessed by the trainer. The apparent lower initial blood IRI concentration in the hard-worked group probably signifies a catecholamine influence, and the minor role of circulating glucose, as a fuel for skeletal muscles in sprint races, until muscle glycogen concentrations fall in man (Hermansen et al. 1970) and probably also in horses (Valberg et al. 1985; Valberg, 1986). The critical horse experiments have not, however, been undertaken. The insulin response extended for several hours following light exercise and a large meal (Fig. 2). Whereas muscle glycogen is the primary fuel in sprint races, liver glycogen and circulating glucose are significant energy sources in extended exercise, in which 
performance might be adversely affected by postprandial insulin secretion. Although adrenalin secreted during exercise would inhibit the secretion of insulin, it would presumably have no effect on the rate of removal of circulating insulin (Krotkiewski et al. 1987), which in extended exercise would assume significance. Nevertheless, there may not be an optimum concentration of blood insulin, even for extended exercise. Although insulin stimulates resting muscle cell uptake of circulating glucose, and counteracts glycogenolysis, it is apparently not required to facilitate glucose transport across contracting muscle cell membranes (Guyton, 1981). This assertion is in accord with the observations in volunteers of Gleeson et al. (1986), but conflicts with that of Costill (1985), where carbohydrate was consumed by athletes in the last hour before exercise. The insulin-stimulated uptake of glucose from the blood resulted in hypoglycaemia, an earlier onset of exhaustion, and probably greater dependence on muscle glycogen. Therefore, the effect of circulating insulin on performance must remain undecided but may be influenced by the timing of carbohydrate consumption and the length of exercise.

Evidence would indicate that in Standardbred horses (Valberg, 1986) glycogen reserves in the gluteus medius muscle are still considerable after trotting at speeds of 750 $\mathrm{m} / \mathrm{min}$ for 13-14 minutes, most glycogen losses occurring in type I and type IIA fibres rich in mitochondria. One would anticipate that galloping would cause a greater loss of glycogen from type IIB fibres, owing to the lower energy yield of anaerobic respiration. This has been confirmed by Hodgson et al. (1984) and Valberg et al. (1985), although fatigue at high speeds is a function not only of glycogen depletion, but also of the intensity of lactate accumulation, and probably of other factors. Amongst trotting horses (Valberg, 1986) the proportion of muscle fibres depleted of glycogen increased with the distance covered. Within the limits of 360 and $600 \mathrm{~m} / \mathrm{min}$ the proportion of depleted fibres was always greater for type I and least for type IIB fibres. After $40 \mathrm{~km}$ at 360 $\mathrm{m} / \mathrm{min}$ a high proportion of type I fibres was depleted. A possible failure of periodic acid Schiff stain to detect changes in intramuscular glycogen concentration exceeding 400 $\mathrm{mmol} / \mathrm{kg}$ dry matter may account for the detectable proportion of partially depleted fibres being less for higher speeds than at $360 \mathrm{~m} / \mathrm{min}$ over a fixed distance of $5-8 \mathrm{~km}$.

Exhaustion during extended exercise of horses is in part a function of the depletion of muscle glycogen, especially in types I and IIA fibres (Essén-Gustavsson et al. 1984). Training increases the amounts of glycogen that may be stored in skeletal muscles of both horses and athletes, and training has an objective of sparing glycogen by increasing fat utilization, and thus increasing the proportion of energy derived from it. The oxidation of free fatty acids (FFA) in the liver yields ketones. Untrained athletes and unfit horses derive energy for muscle contraction to a lesser extent from depot fat than do trained athletes (Rennie et al. 1974), or trained horses (Snow \& MacKenzie, 1977). After exercise there is a rise in blood ketones that is apparently greater in untrained subjects despite lower levels of lipolysis (Rennie et al. 1974), or of FFA mobilization (Kaminsky 1986), probably reflecting lower fat utilization but continued hepatic FFA breakdown. A somewhat similar situation seems to apply to fit and unfit horses (Frape et al. 1979) (Fig. 4), although work intensity was not completely equalized in this study, as measured by heart rate (Frape, 1986). Post-aerobic exercise ketosis in athletes is probably a hepatic $\beta$-adrenergic response during a functional hepatic insulin and glucagon deficiency, as it has been abolished by $\beta$-adrenergic blockade (Adams et al. 1985). These workers speculate that after exercise the hepatocyte is switched to a state in which it is refractory to insulin and glucagon, but responsive to the catecholamines.

The increased muscle glycogen storage and utilization in horses that results from training requires increased daily intakes of starch. Augmented stores of muscle glycogen 




Fig. 4. Plasma 3-hydroxybutyrate concentration during an endurance ride of ( $-\cdots)$ fit and (- - unfit horses (from Frape et al. 1979).

are achievable in athletes, and procedures that lead to glycogen loading are practised by athletes undertaking long-distance events (Williams, 1985). Preliminary evidence indicates that it is possible to glycogen-load skeletal muscles of horses, but no evidence has been advanced that the procedure improves endurance or extends work performance. Indeed the procedure is potentially risky. Laminitis (Garner et al. 1978), endotoxaemia (Sprouse et al. 1987), enterotoxaemia (Carroll et al. 1987), and gastric and caecal tympany (Meyer, 1983; Carroll et al. 1987), are all possible sequelae, although equine rhabdomyolysis is a less likely outcome than previously thought possible (Harris \& Snow, 1986). Horses in training are also subject to a high incidence of gastric ulceration. Although the cause is unknown, it has been suggested (Hammond et al. 1986) that large meals of grain, or stress-induced reduced gastric blood flow, mediated by catecholamines and corticosteroids, may be involved.

With the exception of gastric ulceration, the immediate causative agents of the other metabolic disorders are lactic acid, endotoxins, enterotoxins and gases arising from fermentation. The mechanisms by which feed can initiate the chain of pathological events is now partly understood. The number of chewing movements to which the horse, or pony, subjects feeds of various types differs considerably, whereas the number per min is similar. Four times as many chews are given to $1 \mathrm{~kg}$ long hay compared with $1 \mathrm{~kg}$ oats or pellets (Meyer et al. 1975). In the grazing horse a continuous pattern of feed intake occurs, whereas starchy concentrates are given to stabled horses as one to three meals daily. A discontinuous pattern of this sort can cause a rapid gastric accumulation of dry matter, as the rate of emptying through the pylorus does not differ between feeding regimens (Meyer, 1980). The ratio, filling rate:rate of discharge through the pylorus is 6:1 for roughages and 12-40:1 for mixed feeding, the latter variation depending on the amount of feed given in a meal. The differences seem to be related to the limiting rate at which the ingesta are mixed with the saliva and gastric juice necessary for passage through the pylorus. Following hay consumption the $\mathrm{pH}$ of the contents of the pylorus rapidly attains $2 \cdot 5-3 \cdot 0$, whereas $3 \mathrm{~h}$ after giving a mixed feed the $\mathrm{pH}$ is still 5-6, enabling micro-organisms to grow and produce gas and lactic acid (Meyer, 1983). Moreover, 
gastric emptying is inhibited by excessive DL-lactic acid and volatile fatty acids produced during fermentation of excess carbohydrate (Freeman, 1982) with an accumulation of gas and fluids that causes gastric dilation.

Nevertheless, pyloric outflow rate of dry matter must increase during, and following, large meals of concentrates. Large meals of mixed concentrate feeds effect a large influx of highly-fermentable material to the caecum 3-4 $\mathrm{h}$ after the meal, whereupon a rapid increase in VFA concentration occurs. DL-lactic acid production in the large intestine can rise steeply, and a greater fall in $\mathrm{pH}$ of the medium results than is detected following a meal of roughage (Meyer, 1983). This fall is frequently associated with caecal acidosis and endotoxin release and absorption, with a consequence of laminitis (Gamer et al. 1977). Following the consumption of pelleted diets, or fresh grass, ingesta move much more rapidly to the caecum than following long or chopped hay (Hintz, 1975), and the incidence of laminitis and of colic in horses grazing rapidly growing grass (Osborne, 1985) may rely on a suppression of small-intestinal digestion of soluble carbohydrates and protein by the rapid transit of ingesta to the large intestine.

Interest in fat supplementation of the diet has been stimulated by a dilemma introduced with high daily rates of energy expenditure and the effects of excess starch. McCann et al. (1987) obtained average metabolizable energy values for three fats of $36 \cdot 1$ $\mathrm{MJ} / \mathrm{kg}$. The diets of oats, maize, bran and dried grass, including $150 \mathrm{~g}$ supplementary $\mathrm{fat} / \mathrm{kg}$, were palatable and caused no digestive disturbance. However, each trial lasted 14 $\mathrm{d}$ only, and it is probable that over more extended periods of feed storage and consumption fat instability would precipitate vitamin $E$ deficiency and related problems, unless the stability of the diet was assured and a large supplement of vitamin $E$ was provided.

\section{Micronutrients}

Trace elements. Dietary inadequacies of copper, manganese and zinc have been asserted to be contributory causes of abnormalities in long-bone development under field conditions. However, satisfactory proof is lacking in the horse. The induction of $\mathrm{Cu}$ deficiency by excessive molybdenum and sulphur in protein-rich herbage is less likely to occur in horses than it is in ruminants, as no significant intestinal synthesis of thiomolybdate has been detected (Strickland et al. 1987), owing probably to the location of the vast proportion of intestinal micro-organisms distal to the region from which molybdate is absorbed. Much more convincing evidence exists for field deficiences of selenium. In the western USA, concentrations of $\mathrm{Se}$ in the blood were negatively correlated with the incidence of reproductive disease in mares (Basler \& Holtan, 1981). Blood concentrations were related to natural levels in the diet that ranged from 0.045 to $0.451 \mathrm{mg} / \mathrm{kg}$ dry matter. Nutritional muscular dystrophy in foals resulting from Se deficiency in their dams has been described by investigators, both in the UK and the USA. Finally, a negative correlation has been detected between $\gamma$-glutamyl transferase ( $E C$ 2.3.2.2.) activity in the serum and serum Se concentration in TB undergoing training in the UK (Blackmore et al. 1979). Although all these horses were healthy, those with low concentrations of Se were reported to perform unsatisfactorily. A positive correlation was found between serum, or whole blood, Se of another group of eighty TB in training in the UK and erythrocyte glutathione peroxidase (EC 1.11.1.9) activity.

Vitamin supplementation. The vitamin supplementation of horses and, in particular, of racehorse diets is very variable, and not necessarily in proportion to estimated needs. Several reports indicate that responses may be obtained to dietary supplements of certain vitamins. Comben et al. (1984) demonstrated an improvement in hoof quality of adult horses from dietary biotin supplements. The same response to supplementary biotin was 
observed more recently by Wintzer (1986). What appear to be low circulating levels of 25-hydroxyergocalciferol and of 25-hydroxycholecalciferol, despite the consumption of hay and access by horses to sunlight, were determined by Smith \& Wright (1984) in southern England and by Mäenpää et al. (1987) in Finland. The dietary requirement of exercising horses for $\alpha$-tocopherol has not been established. Ronéus et al. (1986) demonstrated increases in serum, liver and muscle concentrations of vitamin $E$ in the horse with dietary intakes of up to $4.4 \mathrm{mg}$ DL- $\alpha$-tocopheryl acetate/kg body-weight daily (approximately $225 \mathrm{mg} / \mathrm{kg}$ diet), whereas by using a layering haemolysis test for erythrocytes in saline $(9 \mathrm{~g}$ sodium chloride/l) solution, Stowe (1968) concluded that the oral requirement of foals for DL- $\alpha$-tocopherol was only $0.233 \mathrm{mg} / \mathrm{kg}$ body-weight daily, or approximately $11.4 \mathrm{mg} \mathrm{DL}-\alpha$-tocopheryl acetate $/ \mathrm{kg}$ diet. Jackson (1987) concluded that vitamin $\mathrm{E}$ deficiency exacerbates exercise-induced damage to skeletal muscle of athletes, but that the mechanism was unclear. Poole et al. (1988) demonstrated an inhibition of Ca-induced pathological changes in muscle by supplemental vitamin $E$ which may not be related to its role as an antioxidant. However, $\alpha$-tocopherol is an integral part of cellular membranes protecting $\omega-6$ fatty acids from peroxidation. Free radicals generated during exercise may peroxidize linoleic and arachidonic acids in these membranes. These lipid peroxides can decompose to $n$-pentane, which appears in exhaled breath. Lemoyne et al. (1987) detected a negative correlation between breath pentane output and plasma vitamin $\mathrm{E}$ concentration $(r-0.66)$ in human patients. Breath pentane excretion was decreased even in normal subjects after vitamin E supplementation. Whether very high tissue concentrations of $\alpha$-tocopherol in the horse, as determined by Ronéus et al. (1986), are associated with reduced tissue peroxide formation remains to be determined.

Observations indicate lower blood cyanocobalamin concentrations in TB under training than in mares at stud (Frape, 1986). Whether this resulted from an environmental source of vitamin $B_{12}$ available to grazing mares, or a greater tissue demand for the vitamin during training, when starch consumption is considerable and propionate becomes a much more significant energy source, is not known. Nevertheless it is apparent, at least from the biotin evidence, that water-soluble vitamins derived from intestinal microbial synthesis, together with those present naturally in the diet, may not be always adequate to meet the requirements even of adult horses.

\section{Conclusions}

Disorders in the leg growth of foals are not infrequent. Evidence is available that the dietary protein:energy ratio, and the rate of starch intake from supplementary feeds, may not be optimum for normal growth and development, whereas historically inappropriate amounts of dietary $\mathrm{Ca}$ and $\mathrm{P}$ were common shortcomings. Dietary protein is often restricted in an endeavour to reduce the incidence of leg ailments. By contrast free access ('nibbling') by weaned foals to diets containing $140 \mathrm{~g}$ protein $/ \mathrm{kg}$ may reduce a propensity to leg ailments. If this diet includes $400 \mathrm{~g}$ chopped $(70-80 \mathrm{~g}$ protein $/ \mathrm{kg})$ hay $/ \mathrm{kg}$ the concentrated portion of the diet should contain $180 \mathrm{~g}$ protein $/ \mathrm{kg}$, an amount in excess of that found in most TB studs. Trace element status and metabolism are creating greater current interest, and inadequacies of Se and of certain vitamins are cited as causes of nutritional disorders of both growing and adult horses.

Estimates of the chronic requirements of the exercised horse for dietary energy are available so that dietary standards can be established. The immediate source of energy for muscle contraction is provided by muscle glycogen and depot fat, and training is required to establish metabolic pathways of adequate productivity to meet these acute needs. Several metabolic disorders observed in horses given high-energy diets are caused by abnormal activity of the gastrointestinal microflora, resulting from the consumption of 
large starchy meals that can cause endotoxaemia and acidaemia. The dietary protein allowance of many exercised horses is excessive, and this excess may be a contributory cause of both leg disorders, when the dietary $\mathrm{Ca}$ concentration is marginal, and poor racing performance, as a result of an aggravation of an existing metabolic acidosis.

The author gratefully acknowleges the help of Miss Judith Tee, Hinchingbrooke Hospital for extensive help with the computer programme used for data analysis; Dr P. J. Broadbent, University of Aberdeen; Mr S. W. Ricketts, FRCVS of Beaufort Cottage Laboratories, Newmarket; David Evans MRCVS and to Professor J. M. Forbes for helpful criticism of the text.

\section{REFERENCES}

Adams, J. H., Irving, G., Koeslag, J. H., Lochner, J. de V., Sandell, R. C. \& Wilkinson, C. (1985). Equine Veterinary Journal 17, 438-443.

Basler, S. E. \& Holton, D. W. (1981). Proceedings of the Western Section of the American Society of Animal Science 32, 399-400.

Blackmore, D. J., Campbell, C., Dant, C., Holden, J. E. \& Kent, J. E. (1982). Equine Veterinary Journal 14, 139-143.

Blackmore, D. J., Willett, K. \& Agness, D. (1979). Research in Veterinary Science 26, 76-80.

Carroll, C. L., Hazard, G., Coloe, P. J. \& Hooper, P. T. (1987). Equine Veterinary Journal 19, 344-346.

Carroll, C. L. \& Huntington, P. J. (1988). Equine Veterinary Journal 20, 41-45.

Comben, N., Clark, R. J. \& Sutherland, D. J. B. (1984). Veterinary Record 115, 642-645.

Costill, D. L. (1985). Federation Proceedings 44, 364-368.

Essén-Gustavsson, B., Karlström, K. \& Lindholm, A. (1984). Equine Veterinary Journal 16, 197-202.

Evans, D. L. \& Rose, R. J. (1988). Equine Veterinary Journal 20, 94-98.

Frape, D. L. (1986). Equine Nutrition and Feeding. London: Longmans.

Frape, D. L. (1987). Equine Veterinary Journal 19, 265.

Frape, D. L. (1988). Equine Veterinary Journal 20, 163-172.

Frape, D. L., Peace, C. K. \& Ellis, M. (1979). Proceedings of the 30th Annual Meeting European Association for Animal Production H-VI-5.

Freeman, D. E. (1982). In Equine Medicine and Surgery, 3rd ed., p. 505. Santa Barbara: American Veterinary Publications.

Freeman, D. W., Potter, G. D., Schelling, G. T. \& Kreider, J. L. (1988). Journal of Animal Science 66, $407-412$.

Gabel, A. A. (1988). Equine Veterinary Journal 20, 4-5.

Garner, H. E., Hutcheson, D. P., Salem, C., Coffman, J. R. \& Hahn, A. W. (1977). Journal of Animal Science 45, 1037-1041.

Garner, H. E., Moore, J. N., Johnson, J. H., Clark, L., Amend, J. F., Tritschler, L. G., Coffman, J. R., Sprouse, R. F., Hutcheson, D. P. \& Salem, C. A. (1978). Equine Veterinary Journal 10, $249-257$.

Gavin, L. A. \& Moeller, M. (1983). Metabolism 32, 543.

Gibbs, P. G., Potter, G. D., Blake, R. W. \& McMullan, W. C. (1982). Joumal of Animal Science 54, 469.

Glade, M. J. (1983). Equine Veterinary Journal 15, 31-36.

Glade, M. J. (1986). Journal of Equine Veterinary Science 7, 175-189.

Glade, M. J., Beller, D., Bergman, J., Berry, D., Blonder, E., Bradley, J., Cupelo, M. \& Dallas, J. (1985). Nutrition Reports International 31, 649-659.

Glade, M. J., Gupta, S. \& Reimers, T. J. (1984). Journal of Animal Science 59, 658-665.

Glade, M. J. \& Luba, N. K. (1987). American Journal of Veterinary Research 48, 578-582.

Gleeson, M., Greenhaff, P. L. \& Maughan, R. J. (1987). Proceedings of the Physiological Society 108P, C81.

Gleeson, M., Maughan, R. J. \& Greenhaff, P. L. (1986). Proceedings of the Nutrition Society 45, 127A.

Guyton, A. C. (1981). Textbook of Medical Physiology, 6th ed. Philadelphia: W. B. Saunders Co.

Haggendal, J. (1971). In Muscle Metabolism During Exercise, pp. 119-126 [B. Pernow and B. Salin, editors]. New York: Plenum Press.

Hammond, C. J., Mason, D. K. \& Watkins, K. L. (1986). Equine Veterinary Journal 18, 284-287.

Harris, P. \& Snow, D. H. (1986). Equine Veterinary Joumal 18, 346-348.

Hermansen, L., Pruett, E. D., Osnes, J. B. \& Giere, F. A. (1970). Journal of Applied Physiology 29, 13-16. 
Hintz, H. F. (1975). Journal of the South African Veterinary Association 46, 13-17.

Hintz, H. F., Schryver, H. F. \& Lowe, J. E. (1976). Proceedings of the Cornell Nutrition Conference for Feed Manufacturers, pp. 94-96. Ithaca, NY: Cornell University.

Hodgson, D., Rose, R., Allen, J. \& Dimauro, J. (1984). Research in Veterinary Science 36, 169-173.

Irvine, C. H. G. (1983). In Equine Exercise Physiology, Proceedings of the First International Conference, Oxford, pp. 377-388 [D. H. Snow, S. G. B. Persson and R. J. Rose, editors]. Cambridge: Granta Editions.

Jackson, M. J. (1987). Proceedings of the Nutrition Society 46, 77-80.

Jeffcott, L. B., Rossdale, P. D., Freestone, J., Frank, C. J. \& Towers-Clark, P. F. (1982). Equine Veterinary Journal 14, 185-198.

Kaminsky, L. A., Knowlton, R. G., Perkins, R. M. \& Hetzler, R. K. (1986). American Journal of Clinical Nutrition 44, 603-609.

Krotkiewski, M., Szelachowska, M. \& Górski, J. (1987). American Journal of Clinical Nutrition 46, 976-979.

Kunkel, M. E., Roughead, Z. K., Nichtr. E. A. \& Navia, J. M. (1986). British Journal of Nutrition 55, 79-86.

Lemoyne, M., Van Gossum, A., Kurian, R., Ostro, M., Axler, J. \& Jeejeebhoy, K. N. (1987). American Journal of Clinical Nutrition 46, 267-272.

McCann, J. S., Meacham, T. N. \& Fontenot, J. P. (1987). Journal of Animal Science 65, 1019-1026.

Mäenpää, P. H., Lappetelainen, R. \& Virkkunen, J. (1987). Equine Veterinary Journal 19, 237-240.

Meyer, H. (1983). Proceedings of the Horse Nutrition Symposium, Uppsala, pp. C95-109.

Meyer, H., Ahlswede, L. \& Pferdekamp, M. (1980). Deutsch tierärtzliche Wochenschrift 87, 43-47.

Meyer, H., Ahlswede, L. \& Reinhard, H. J. (1975). Deutsch tierärtzliche Wochenshrift 82, 54-58.

Oftedal, O. T., Hintz, H. F. \& Schryver, H. F. (1983). Journal of Nutrition 113, 2096-2106.

Orton, R. K., Hume, 1. D. \& Leng, R. A. (1985). Equine Veterinary Journal 17, 381-385.

Osborne, M. (1985). Proceedings of the Equine Colic Research Symposium, University of Georgia, pp. 21-23.

Pagan, J. D. \& Hintz, H. F. (1986a). Journal of Animal Science 63, 822-830.

Pagan, J. D. \& Hintz, H. F. (1986b). Journal of Animal Science 63, 815-821.

Phillips, L. S. (1986). Metabolism 35, 78-87.

Poole, J., Jackson, M. J. \& Edwards, R. H. T. (1988). Proceedings of the Nutrition Society 47, 34 A.

Rennie, M. J., Jennett, S. \& Johnson, R. H. (1974). Quarterly Journal of Experimental Physiology 59, 201-212.

Ronéus, B. O., Hakkarainen, R. V. J., Lindholm, C. A. \& Työppönen, J. T. (1986). Equine Veterinary Journal 18, 50-58.

Schryver, H. F., Meakin, D. W., Lowe, J. E., Williams, J., Soderholm, L. V. \& Hintz, H. F. (1987). Equine Veterinary Journal 19, 280-287.

Smith, B. S. W. \& Wright, H. (1984). Veterinary Record 115, 579.

Snow, D. H. (1980). In Proceedings of the Third International Symposium of Equine Medical Control, [T. Tobin, J. W. Blake \& W. E. Woods, editors]. Lexington, KY: University of Kentucky.

Snow, D. (1987). In Practice Jan, pp. 26-30.

Snow, D. H. \& MacKenzie, G. (1977). Equine Veterinary Journal 9, 134-140.

Snow, D. H., Summers, R. J. \& Guy, P. S. (1979). Research in Veterinary Science 27, 22-29.

Snow, D. H. \& Rose, R. J. (1981). Equine Veterinary Journal 13, 195-197.

Sprouse, R. F., Garner, H. E. \& Green, E. M. (1987). Equine Veterinary Journal 19, 25-28.

Stowe, H. D. (1968). American Journal of Clinical Nutrition 21, 135-143.

Strickland, K., Smith, F., Woods, M. \& Mason, J. (1987). Equine Veterinary Journal 19, $50-54$.

Valberg, S. (1986). Equine Veterinary Journal 18, 479-484.

Valberg, S., Essén-Gustavsson, B., Lindholm, A. \& Persson, S. (1985). Equine Veterinary Journal 17, 438-443.

Williams, C. (1985). Proceedings of the Nutrition Society 44, 245-256.

Wintzer, H. J. (1986). Tierartzliche Praxis 14, 495-500. 